\title{
DYSFUNCTIONALBEHAVIOR ATAS INTERAKSI REINFORCEMENT CONTIGENCY DAN MOTIVASI EKSTRINSIK SUBORDINATE
}

Fara Fitriyani dan Emma Suryani

\author{
Akuntansi, Universitas Sultan Ageng Tirtayasa, Serang \\ Manajemen, Universitas Sultan Ageng Tirtayasa, Serang \\ fara_0606@untirta.ac.id,emma_7181@yahoo.com
}

Diterima 11 Agustus 2018, Disetujui 20 Agustus 2018

\begin{abstract}
Abstrak
Penelitian ini bertujuan untuk mengetahui pengaruh tekanan ketaatan pada senjangan anggaran dan interaksi antara tekanan kepatuhan dan kontingensi penguatan pada senjangan anggaran. Populasi penelitian ini adalah bawahan di perguruan tinggi di Provinsi Banten. Metode pengambilan sampel menggunakan purposive sampling dengan jumlah sampel yang memenuhi kriteria 91 responden. Kuesioner diuji dengan uji reliabilitas dan uji validitas, kemudian asumsi klasik diuji termasuk uji normalitas, uji multikolinearitas, dan uji heteroskedastisitas. Maka pengujian hipotesis dilakukan dengan analisis regresi tunggal dan analisis regresi berganda. Hasilnya menunjukkan bahwa semua variabel dapat diandalkan dan valid dan memenuhi uji asumsi klasik. Hasil analisis hipotesis menunjukkan bahwa tekanan kepatuhan mempengaruhi senjangan anggaran, ada interaksi antara tekanan kepatuhan dan kontingensi penguatan terhadap senjangan anggaran.
\end{abstract}

Kata Kunci : tekanan kepatuhan, kontingensi penguatan, dan senjangan anggaran.

\begin{abstract}
This study aims to determine the effect of compliance pressure on budgetary slack and the interaction between compliance pressure and strengthening contingency on budgetary slack. The population of this study is subordinate to a college in Banten Province. The sampling method uses purposive sampling with a number of samples that meet the criteria of 91 respondents. The questionnaire was tested by reliability test and validity test, then the classical assumptions were tested including normality test, multicollinearity test, and heteroscedasticity test. Then hypothesis testing is done by single regression analysis and multiple regression analysis. The results show that all variables are reliable and valid and meet the classic assumption test. The results of hypothesis analysis indicate that compliance pressure affects budgetary slack, there is an interaction between compliance pressure and a strengthening contingency on budgetary slack.
\end{abstract}

Keywords: compliance pressure, strengthening contingency, and budgetary slack. 


\section{PENDAHULUAN}

\section{Latar Belakang}

Setiap organisasi dalam melaksanakan tugas yang diemban mutlak mempunyai rencana-rencana yang disusun dan dijadikan pedoman dalam menjalankan organisasinya. Sejalan dengan tugas yang diemban tersebut, maka organisasi merumuskan berbagai kebijakan yang dituangkan dalam bentuk anggaran. Melalui anggaran, akan diketahui seberapa besar kemampuan organisasi dalam melaksanakan berbagai urusan yang menjadi wewenangnya dan faktor-faktor apa saja yang mempengaruhinya.

Sebagai sebuah institusi yang berada di bawah payung hukum dan peraturan Republik Indonesia, perusahaan selalu melaksanakan operasionalnya sesuai dengan Undang-Undang yang berlaku. Seperti apapun perubahan peraturan atau Undangundangnya, persyaratan finansial selalu menjadi prasyarat yang harus dipenuhi oleh perusahaan untuk mendapatkan status badan hukum tertentu. Kelayakan finansial akan berkaitan erat dengan proses penyusunan anggaran, seperti yang di ungkapkan Kadarman (2001) penganggaran adalah perumusan rencana dalam angka-angka untuk periode tertentu di masa depan. Anggaran disusun oleh manajemen untuk jangka waktu satu tahun bertujuan untuk membawa perusahaan ke kondisi tertentu yang diinginkan dengan sumber daya tertentu yang diperhitungkan.

Peran perilaku manusia dalam organisasi diharapkan dapat memberikan keuntungan pada organisasi. Agar tujuan penganggaran tercapai, yaitu melibatkan bawahan (subordinate) untuk merencanakan masa depan sehingga dapat memberikan informasi sumber daya yang dapat meningkatkan kualitas pengambilan keputusan, sebagai standar bagi evaluasi kinerja dan meningkatkan komunikasi dan koordinasi dari semua bagian organisasi.

Masalah yang sering muncul dari adanya keterlibatan subordinate dalam penyusunan anggaran adalah dysfunctional behavior. Jaworski dan Young $(1992,18)$ mendefinisikan dysfunctional behavior sebagai suatu tindakan yang dilakukan subordinate untuk memanipulasi elemen-elemen sistem pengendalian yang digunakan oleh kepentingan subordinate dalam mencapai tujuan yang diinginkan subordinate. Menurut Soobaroyen (2006) dysfunctional behavior yang dilakukan oleh subordinate dalam memanipulasi elemen-elemen sistem pengendalian manajemen ada dua bentuk yaitu manipulasi informasi (dysfunctional behaviorinformation manipulation) dan manipulasi ukuran kinerja didalam pemilihan tindakan (dysfunctional behavior-gaming).

Budgetary slack merupakan salah satu bentuk dysfunctional behavior. Budgetary slack adalah perbedaan antara jumlah anggaran yang diajukan oleh subordinate dengan jumlah estimasi terbaik yang telah diajukan dan dilakukan pada saat penyusunan anggaran (Anthony \& Govindarajan, 2007). Selain itu, Slack sering dikaitkan dengan anggaran dan umumnya dianggap sebagai bagian dari penyimpangan anggaran antara aktual dan standar yang sengaja diciptakan oleh subordinate untuk membuat target anggaran lebih mudah untuk dicapai (Dunk, 1993).

Penelitian tentang budgetary slack mengindikasikan bahwa subordinate yang menginginkan dalam membuat slack. Penelitian Young (1985) dan Merchant (1985) telah menguji secara empiris bahwa budgetary slack terjadi karena subordinate memberi informasi yang bias kepada atasan (superior) dengan cara melaporkan biaya yang lebih besar atau melaporkan pendapatan yang lebih rendah. Hasil penelitian menunjukkan bahwa karena adanya keinginan untuk menghindari resiko, subordinate yang terlibat dalam penyusunan anggaran cenderung untuk melakukan budgetary slack. Semakin tinggi resiko, subordinate yang berpartisipasi dalam penyusunan anggaran akan melakukan budgetary slack. Hasil penelitian tersebut tidak konsisten dengan hasil penelitian Dunk (1993). Hasil penelitian menyatakan bahwa interaksi antara partisipasi, informasi asimetri dan budget emphasis mempunyai hubungan yang negatif dengan budgetary slack tetapi korelasinya signifikan. Hal ini ketika partisipasi, informasi asimetri dan budget emphasis tinggi maka budgetary slack menjadi rendah dan sebaliknya.

Berbeda dengan penelitian di atas, beberapa penelitian lain mengindikasikan bahwa slack dapat diciptakan karena keinginan dari atasan langsung (superior) sebagai manajer tingkat atas dengan menekan subordinate sebagai manajer tingkat menengah dan bawah untuk melakukan perintah sesuai permintaan atasan. Tekanan ketaatan (obedience pressure) merupakan jenis tekanan pengaruh sosial yang dihasilkan ketika individu dihadapkan dengan perintah otoritas dari perilaku orang lain. Adanya tekanan sosial ini akan sangat mungkin meningkatkan penalaran moral individu dalam melakukan slack pada proses penganggaran. Penelitian tentang tekanan ketaatan (obedience 
pressure) telah dilakukan oleh DeZoort dan Lord (1994), hasil penelitian mengindikasikan adanya pengaruh dari tekanan atasan pada judgment yang diambil auditor pemula. Penelitian Davis et al. (2006) mengevaluasi kerentanan terhadap tekanan ketaatan bagi akuntan manajemen untuk menciptakan budgetary slack dengan melanggar kebijakan perusahaan.

Manusia merupakan makhluk sosial yang biasanya terdorong melakukan sesuatu karena adanya motivasi. Motivasi merupakan keadaan diri pribadi seseorang yang mendorong keinginan individu untuk melakukan kegiatan-kegiatan tertentu guna mencapai suatu tujuan (Handoko dan Sukanto, 1992). Motivasi untuk melakukan suatu tindakan dapat timbul dari faktor internal dan faktor eksternal dari individu tersebut. Motivasi internal akan muncul ketika individu dihadapkan pada kebutuhan dan keinginan dari dalam diri seseorang tersebut, sedangkan motivasi eksternal akan timbul ketika individu tersebut dipengaruhi oleh faktor di luar individu tersebut seperti kebijakan perusahaan, perintah atasan, dan suasana kerja lainnya.

Adanya tekanan ketaatan ini tidak semerta-merta membuat seseorang tergerak untuk melakukan budgetary slack. Keefektifan tujuan anggaran dipengaruhi oleh faktor-faktor kondisional (Brownel, 1980) dan lingkungan organisasi (Hartmann, 1999). Selain itu, organisasi harus mempertimbangkan segi perilaku subordinate (Cherrington dan Cherrington, 1973). Cherrington (1973) dalam studi partisipasi anggaran menemukan variabel moderator lain yaitu struktur reward yang memiliki hubungan antara dampak partisipasi anggaran dan kepuasan kerja (Brownel, 1980).

Pemberian reward bagi subordinate yang berhasil mencapai tujuan organisasi, memotivasi subordinate untuk berkompetisi dengan memberikan yang terbaik bagi organisasi demi mendapatkan reward tersebut, karena reward dapat memenuhi sense of accomplishment, value attainment dan kepuasan subordinate. Subordinate akan semakin menjauhkan diri dari perilaku yang buruk karena takut mendapat punishment yang bisa mengurangi sense of accomplishment. Reinforcement contingency dapat menjadi anteseden karena subordinate akan lebih termotivasi untuk berprilaku baik demi mendapatkan reward untuk memenuhi sense of accomplishment dan kepuasan.

Penelitian ini mempunyai beberapa kontribusi; 1) Penelitian mengenai partisipasi anggaran sudah banyak dikaji pada bidang akuntansi manajemen. Akan tetapi sebatas pengetahuan peneliti, tekanan ketaatan dalam kaitannnya dengan reinforcement contingency sangat sedikit ditemui. Oleh karena itu, penelitian ini memberi manfaat bagi perkembangan ilmu akuntansi manajemen tentang bagaimana pengaruh interaksi reinforcement contingency dan tekanan ketaatan terhadap budgetary slck, 2) penelitian mengenai reinforcement contingency selama ini menggunakan studi eksperimen dan studi kasus. Pada penelitian ini penulis membuat rekonstruksi baru dengan mengembangkan kuesioner baru. Sehingga penelitian ini diharapkan menjadi dokumen akademik yang berguna dan menjadi bahan acuan civitas akademika untuk penelitian lebih lanjut di masa mendatang.

\section{Tujuan Penelitian}

Untuk mengetahui apakah terdapat pengaruh tekanan ketaatan terhadap budgetary slack. Untuk mengetahui apakah terdapat interaksi antara reinforcement contigency dan tekanan ketaatan terhadap penciptaan budgetary slack.

\section{KAJIAN TEORI}

\section{Teori Keagenan}

Teori keagenan merupakan konsep yang menjelaskan hubungan kontraktual antara principals dan agents. Menurut Choudhury (1985) teori keagenan digunakan untuk menjelaskan budgetary slack dalam proses anggaran, teori keagenan memfokuskan bagaimana cara membuat desain kontrak insentif yang dapat digunakan untuk memaksimalkan laba dihubungkan dengan asimetri informasi antara principals dan agents, kesesuaian pendapatan pribadi oleh agents, dan ketidakpastian lingkungan yang berakibat pada hasil keputusan agents.

\section{Tekanan Ketaatan}

Dalam beberapa situasi sosial, seseorang memandang orang lain atau kelompok sebagai pemilik otoritas yang sah untuk mempengaruhi perilaku orang tersebut. Norma sosial membolehkan pihak yang memiliki otoritas untuk mengajukan permintaan dan memaksa agar bawahan mematuhinya. Kepatuhan didasarkan pada keyakinan bahwa otoritas memiliki hak untuk meminta (Taylor et al. 2009).

Teori ketaatan menyatakan bahwa individu yang memiliki kekuasaan merupakan suatu sumber yang dapat mempengaruhi perilaku orang dengan perintah yang diberikannya, hal ini disebabkan oleh 
keberadaan kekuasaan atau otoritas yang merupakan bentuk legitimate power atau kemampuan atasan untuk mempengaruhi bawahan karena ada posisi khusus dalam struktur hierarki organisasi (Hartanto dan Indra, 2001).

Paradigma ketaatan pada kekuasaan ini dikembangkan oleh Milgram yang dikatakan dalam teorinya bahwa bawahan yang mengalami tekanan ketaatan dari atasan akan mengalami perubahan psikologis dari seseorang yang berperilaku otonomis menjadi perilaku agen. Perubahan perilaku ini terjadi karena bawahan tersebut merasa menjadi agen dari sumber kekuasaan, dan dirinya terlepas dari tanggung jawab atas apa yang dilakukannya.

Penelitian Hartanto dan Indra (2001) memberi tekanan pada pengaruh normatif dari tekanan ketaatannya Milgram (1974). Milgram (1965) dalam Hartanto dan Indra (2001) menemukan bukti yang menunjukkan bahwa orang normal dapat melakukan tindakan destruktif jika menghadapi tekanan besar dari otoritas yang sah. Orang yang dalam kehidupan sehari-harinya bertanggung jawab dan terhormat bisa jadi tertekan oleh otoritas dan mau saja melakukan tindakan kejam dalam situasi tertekan.

\section{Reinforcement Contingency}

Reinforcement theory menjelaskan bahwa penguatan (reinforcement) dapat mengendalikan perilaku (Purnamasari dan Crismastuti, 2006). Reinforcement Contingency adalah desain sistem kontrol untuk menguatkan kontekstual organisasi agar dapat mengendalikan perilaku melalui tiga prinsip dasar yaitu: 1) Konsekuensi dengan memberikan reward untuk meningkatkan perilaku, 2) Konsekuensi dengan memberikan punishment untuk menurunkan perilaku, dan 3) Konsekuensi tanpa adanya reward dan punishment untuk memadamkan perilaku (Purnamasari dan Crimastuti, 2006 p 7). Prinsip dasar reinforcement contingency adalah mengembangkan stimulus response (SR). Pada umumnya kekuatan stimulus response akan meningkat apabila ada kejadian positif sebagai pengaruh dari reward, dan menurun jika ada punishment. Dengan kata lain, stimulus muncul apabila individu merasakan nilai yang positif. Jika output yang dihasilkan berupa efek yang menyenangkan individu tersebut, kemungkinan ia akan mengulanginya (Cherrington dan Cherrington,1973).

\section{Budgetary Slack}

Budgetary slack adalah tindakan yang secara sengaja membiaskan target kinerja berdasarkan tingkat yang diharapkan oleh bawahan (Hartmann dan Maas; 2010). Sedangkan Anthony dan Govindarajan (2007) mendefinisikan budgetary slack sebagai perbedaan antara jumlah anggaran yang diajukan oleh bawahan dengan jumlah estimasi yang terbaik dari organisasi dan dibuat agar bawahan lebih mudah mencapai target. Bawahan cenderung mengajukan anggaran dengan merendahkan pendapatan dan menaikkan biaya dibandingkan dengan estimasi terbaik dari yang diajukan, sehingga target akan lebih mudah tercapai.

Budgetary slack timbul, disatu sisi, jika bawahan memiliki informasi yang lebih besar dibanding atasan (Waller, 1998), dan disisi lain jika kinerja individu diukur berdasarkan anggaran. Individu mungkin mencari cara untuk melindungi diri mereka dari risiko tidak tercapainya target anggaran dan stigma ini umumnya menimbulkan pencapaian yang lebih rendah (Lukka, 1988).

\section{Kerangka Pemikiran dan Pengembangan Hipotesis}

\section{Tekanan Ketaatan dan Budgetary Slack}

Proses penetapan anggaran merupakan subyek konflik karena terlalu subyektif dan rentan terhadap berbagai jenis pengaruh (Lukka, 1988). Konflik utama manajemen untuk akuntan dalam skenario anggaran adalah antara keinginan manajemen untuk melayani sebagai fitur kontrol dan manajemen lokal mempertimbangan pengaruh sosial dan insentif lain yang mempengaruhi penciptaan budgetary slack. Salah satu konflik peran utama pada akuntan manajemen dalam sebuah penganggaran adalah keinginan manajemen corporate untuk mengendalikan anggaran dan manajemen lokal (pusat pertanggungjawaban) untuk mengamankan anggaran yang lebih mudah dicapai.

Davis et al. (2006) menjelaskan bahwa masalah slack anggaran telah mendapat perhatian yang cukup besar dalam literatur akuntansi manajemen tapi masih sedikit pengetahuan tentang bagaimana para manajer memahami slack anggaran, bagaimana mereka merespons pada tekanan atasan untuk membuat slack dengan melanggar kebijakan perusahaan, dan apakah tekanan tersebut menciptakan ambivalensi etis. Davis et al. (2006) melakukan eksperimen pada 77 Akuntan Manajemen dengan hasil bahwa meskipun dengan persepsi etis hampir setengah dari partisipan melanggar kebijakan dan menciptakan slack ketika dihadapkan dengan tekanan ketaatan dari atasan langsung. Berdasarkan hasil penelitian di atas, penelitian ini menguji apakah tekanan ketaatan yang tidak sesuai atas perintah dari 
atasan langsung (superior) memotivasi subordinate mengubah rekomendasi anggaran awal mereka dengan memasukkan slack. Hipotesis yang diajukan sebagai berikut:

$\mathbf{H}_{1}$ : Subordinate dibawah tekanan dari atasan (superior) untuk melanggar kebijakan anggaran dan menciptakan budgetary slack, akan menghasilkan rekomendasi anggaran yang lebih tinggi dibandingkan dengan estimasi awal mereka

Interaksi Reinforcement Contigency dan Tekanan Ketaatan terhadap Budgetary Slack

Reinforcement Contingency memberikan motivasi subordinate atas tindakan yang diambil oleh anggota organisasi (Purnamasari dan Crismastuti, 2006). Motivasi tersebut akan menghasilkan nilai positif bagi subordinate untuk bekerja lebih baik (Ryan and Deci 2000b; Gagne and Deci 2005 dalam Bernard Wong, et al 2010 p 140). Salah satu aspek yang terdapat pada reinforcement contingency adalah motivasi subordinate untuk bekerja lebih giat karena ada tawaran reward yang diberikan oleh organisasi kepada subordinate yang memiliki kinerja baik dan berprestasi. Di pihak lain, punishment yang diberikan akibat ketidakberhasilan subordinate memberikan pengaruh positif kepada subordinate karena subordinate mau bekerja lebih giat untuk menghindari punishment.

Keprihatinan atas penilaian etis akan timbul dalam situasi di mana ada konflik antara kepentingan pribadi dengan kepentingan moral terhadap orang lain (Bowie dan Duska, 1990). Hobson, et al (2011) juga menyatakan bahwa skema pembayaran yang menginduksi slack akan menghasilkan kerangka moral yang bertentangan dengan norma-norma sosial seperti kejujuran atau tanggung jawab. Bagaimana subordinate merespon tekanan atasan untuk membuat slack dengan melanggar kebijakan perusahaan, dan apakah tekanan tersebut berinteraksi dengan reinforcement contingency dalam menciptakan budgetary slack. Sehingga hipotesis yang dikembangkan adalah:

$\mathbf{H}_{\mathbf{2}}$ : Ada interaksi antara reinforcement contingency dan tekanan ketaatan yang mempengaruhi budgetary slack

\section{METODE}

\section{Populasi dan Sampel}

Populasi dalam penelitian ini adalah seluruh subordinate di Perguruan Tinggi Propinsi Banten khususnya di Kota Serang. Metode pengambilan sampel dalam penelitian ini menggunakan metode purposive sampling yaitu pemilihan sekelompok subyek didasarkan atas ciri-ciri atau sifat-sifat tertentu yang dipandang mempunyai sangkut paut yang erat dengan ciri-ciri atau sifat-sifat populasi yang sudah diketahui sebelumnya (Sutrisno, 1996). Sampel ditentukan dengan syarat sebagai berikut: 1) Subordinate merupakan middle management level dalam Perguruan Tinggi; 2) Subordinate terlibat dalam proses penyusunan anggaran Perguruan Tinggi; 3) Subordinate mempunyai masa jabatan paling sedikit satu tahun.

\section{Uji Hipotesis}

Teknik yang digunakan dalam menganalisis tingkat signifikansi untuk masing-masing variabel independen terhadap variabel dependen adalah model statistika analisis regresi linier sederhana (single regression analysis) dan analisis regresi linier berganda (multiple regression analysis). Adapun rumus regresi sesuai model dalam penelitian ini adalah sebagai berikut:

\section{Model Regresi Linier Sederhana.}

Analisis ini digunakan untuk menguji pengaruh satu variabel independen terhadap variabel dependen yaitu menguji pengaruh tekanan ketaatan terhadap budgetary slack $\mathrm{Y}=\beta_{0}+\beta_{1} \mathrm{X}_{1}+\mathrm{e}$

\section{Model Regresi Linier Berganda.}

Analisis ini digunakan untuk menguji pengaruh dua atau lebih variabel independen terhadap variabel dependen yaitu menguji pengaruh tekanan ketaatan terhadap budgetary slack dengan melalui reinforcement contingency sebagai variabel moderating

$$
\mathrm{Y}=\beta_{0}+\beta_{1} \mathrm{X}_{1}+\beta_{2} \mathrm{X}_{2}+\beta_{3} \mathrm{X}_{1} \mathrm{X}_{2}+\mathrm{e}
$$

Keterangan:

$$
\begin{aligned}
\beta_{0} & =\text { Konstanta } \\
\mathrm{Y} & =\text { Budgetary Slack } \\
\mathrm{X}_{1} & =\text { Tekanan Ketaatan } \\
\mathrm{X}_{2} & =\text { Reinforcement Contigency } \\
\mathrm{X}_{1} \mathrm{X}_{2}= & \text { Interaksi antara tekanan ketaatan } \\
& \text { dan reinforcement contingency } \\
\beta_{1-3}= & \text { Koefisien regresi } \\
\mathrm{e}= & \text { eror }
\end{aligned}
$$

Teknik analisis yang digunakan adalah uji interaksi atau sering disebut dengan Moderated Regression Analysis (MRA), merupakan model regresi linier berganda dimana dalam persamaan regresinya mengandung perkalian dua atau lebih variabel independennya. Hipotesis diuji dengan membandingkan tingkat signifikansi t dengan 0,05 
( $\mathrm{a}=5 \%$ ). Apabila tingkat signifikansi $\mathrm{t} \leq 0,05$, maka hipotesis diterima.

\section{HASIL DAN PEMBAHASAN}

\section{Hasil Uji Hipotesis}

\section{Pengujian Hipotesis 1}

Untuk mengetahui adanya pengaruh antara tekanan ketaatan terhadap budgetary slack, digunakan uji regresi linier sederhana. Berdasarkan hasil pengujian yang dilakukan diperoleh nilai-nilai yang tercantum dalam tabel 4

Tabel 4

Hasil Regresi Pengaruh Tekanan Ketaatan terhadap Budgetary Slack

\begin{tabular}{lcccc}
\hline \multicolumn{1}{c}{ Variabel } & $\begin{array}{c}\text { Nilai } \\
\text { Koefisien }\end{array}$ & $\begin{array}{c}\text { Standar } \\
\text { Error }\end{array}$ & $\begin{array}{c}t- \\
\text { value }\end{array}$ & $\begin{array}{c}p \text { - } \\
\text { value }\end{array}$ \\
\hline Konstansta & 3,394 & 0,985 & 3,447 & 0,001 \\
Tekanan & 0,716 & 0,079 & 9,076 & 0,000 \\
Ketaatan & \multicolumn{4}{c}{} \\
\hline \multicolumn{4}{c}{ Square $=48,1 \% \mathrm{~F}=82,365 p=0,000$} \\
\hline
\end{tabular}

Sumber: data primer diolah

Regresi sederhana di atas menunjukkan bahwa nilai $R^{2}$ sebesar $48,1 \%$ yang berarti variabel budgetary slack dapat dijelaskan oleh variabel tekanan ketaatan sekitar 48,1\% dan sisanya 51,9\% dijelaskan oleh variabel lain diluar model ini. Selain itu, nilai $\mathrm{F}$ hitung sebesar 82,36 dengan tingkat signifikansi 0,000 jauh dibawah 0,05. Pengujian terhadap model penelitian menunjukan bahwa model yang diusulkan dalam penelitian ini cukup fit, sehingga model tersebut dapat digunakan untuk mengkonfirmasi hasil antara kesesuaian teoritis dan pengujian secara empiris.

Hipotesis 1 menyatakan bahwa tekanan ketaatan berpengaruh positif terhadap budgetary slack. Pada tabel 4.1, nilai koefisien regresi positif sebesar 0,716 dengan probabilitas 0,000 . Nilai t hitung variabel tekanan ketaatan sebesar 9,076 sedangkan nilai t tabel pada tingkat signifikansi 5\% dan df = $88(91-3)$ sebesar 1,662 (dapat dilihat pada tabel distribusi t) sehingga t hitung $>$ t tabel $(9,076>1,662)$. Hasil ini menunjukkan bahwa variabel tekanan ketaatan berpengaruh positif dan signifikan terhadap variabel budgatery slack, sehingga dapat disimpulkan menerima hipotesis 1 yaitu tekanan ketaatan berpengaruh positif dan signifikan terhadap budgatery slack.

Bawahan dibawah tekanan ketaatan dari atasan langsung untuk melanggar kebijakan anggaran perusahaan dan menciptakan budgetary slack, akan menghasilkan rekomendasi anggaran yang lebih tinggi dibandingkan dengan estimasi awal mereka. Hasil penelitian ini sesuai dengan hasil penelitian Davis et al. (2006) bahwa partisipan akuntan manajemen melanggar kebijakan dan menciptakan slack ketika dihadapkan dengan tekanan ketaatan dari atasan langsung.

\section{Pengujian Hipotesis 2}

Pengujian hipotesis 2 untuk mengetahui adanya pengaruh interaksi antara variabel reinforcement contingency dan tekanan ketaatan terhadap budgetary slack dengan menggunakan uji interaksi atau disebut moderated regretion analysis. Berdasarkan hasil pengujian yang dilakukan diperoleh nilai-nilai yang tercantum dalam tabel 5

Tabel 5

Interaksi Reinforcement Contingency dan Tekanan Ketaatan Terhadap Budgetary Slack

\begin{tabular}{lcccc}
\hline Variabel & $\begin{array}{c}\text { Nilai } \\
\text { Koefisien }\end{array}$ & $\begin{array}{c}\text { Standar } \\
\text { Error }\end{array}$ & $\begin{array}{c}t- \\
\text { value }\end{array}$ & $\begin{array}{c}p- \\
\text { value }\end{array}$ \\
\hline Konstansta & $-5,734$ & 3,459 & $-1,658$ & 0,101 \\
TK & 1,408 & 0,286 & 4,924 & 0,000 \\
RC & 1,095 & 0,398 & 2,749 & 0,007 \\
TK x RC & $-0,083$ & 0,033 & $-2,542$ & 0,013 \\
\hline \multicolumn{4}{c}{$R$ Square $=52,8 \% \mathrm{~F}=32,470$} & $p=0,000$ \\
\hline
\end{tabular}

Sumber: data primer diolah

Regresi linier berganda di atas menunjukkan bahwa nilai $R^{2}$ sebesar 52,8 \% yang berarti variabel budgetary slack dapat dijelaskan oleh variabel tekanan ketaatan, reinforcement contingency dan variabel moderating sekitar 52,8\% dan sisanya 47,2\% dijelaskan oleh variabel lain diluar model ini. Nilai F hitung sebesar 32,470 dengan tingkat signifikansi 0,000 jauh dibawah 0,05 . Pengujian terhadap model penelitian menunjukan bahwa model yang diusulkan dalam penelitian ini dapat digunakan untuk mengkonfirmasi hasil antara kesesuaian teoritis dan pengujian secara empiris.

Hipotesis 2 menyatakan bahwa ada interaksi antara reinforcement contingency dan tekanan ketaatan yang mempengaruhi budgetary slack. Nilai koefisien regresi sebesar $-0,083$ dengan probabilitas 0,013 . Nilai $t$ hitung sebesar $-2,542$ sedangkan nilai $t$ tabel pada tingkat signifikansi 5\% dan df = 88 (91-3) sebesar 1,662 (dapat dilihat pada tabel distribusi t) sehingga $t$ hitung $>t$ tabel $(2,542>1,662)$. Hasil ini menunjukkan bahwa variabel reinforcement contingency berpengaruh terhadap pengaruh antara tekanan ketaatan dan budgetary slack. Berdasarkan hal tersebut berarti terdapat pengaruh interaksi antara reinforcement contingency dan tekanan ketaatan terhadap budgetary slack. Dengan demikian dapat disimpulkan bahwa 
reinforcement contingency merupakan variabel pemoderasi pengaruh tekanan ketaatan terhadap budgetary slack.

Semakin tinggi reinforcement contingency, tekanan ketaatan tidak mempengaruhi subordinate untuk melakukan budgetary slack. Sedangkan semakin rendah reinforcement contingency, tekanan ketaatan mempengaruhi subordinate untuk melakukan budgetary slack. Reinforcement contigency berpengaruh positif terhadap kinerja organisasi karena reinforcement contigency dapat membuat pegawai menjadi ingin mencapai target dan tujuan perusahaan. Dampak dari stimulus ini, pegawai memiliki komitmen organisasi karena perasaan ingin bertahan dalam organisasi, rasa memiliki, rela berkorban demi organisasi akan bertambah sehingga dapat meningkatkan kinerja organisasi. Reinforcement Contingency memberikan motivasi subordinate atas tindakan yang diambil oleh anggota organisasi (Purnamasari dan Crismastuti, 2006). Motivasi tersebut akan menghasilkan nilai positif bagi subordinate untuk bekerja lebih baik (Ryan and Deci 2000b; Gagne and Deci 2005 dalam Bernard Wong, et al 2010 p 140).

\section{SIMPULAN DAN SARAN}

\section{Simpulan}

Dari hasil pengujian dapat disimpulkan bahwa: 1) Terdapat pengaruh tekanan ketaatan terhadap budgetary slack; 2) Terdapat interaksi antara reinforcement contingency dan tekanan ketaatan yang mempengaruhi budgetary slack

\section{Saran}

Penelitian ini memiliki beberapa keterbatasan antara lain sampel penelitian sedikit. Hal ini terjadi karena perguruan tinggi yang dijadikan sampel hanya perguruan tinggi yang ada di Kota Serang. Selain itu sampel penelitian ini hanya satu sektor yaitu sektor Pendidikan. Jadi penelitian ini tidak dapat digeneralisasi pada sektor yang berbeda. Penulis menyarankan agar penelitian selanjutnya memperluas sektor yang diteliti sehingga sampel yang diperoleh dapat lebih banyak.

\section{DAFTAR PUSTAKA}

Anthony, R. N. dan V. Govindarajan. 2007. Management Control System. McGraw-Hill Education: Irwin.

Blanchette, Danielle; Claude Pilote dan Jean Cadieux. 2002. Manager's Moral Evaluation of Budgetary Slack Creation. www.accounting.rutgers.Edu/ raw/aaa/ 2002annual/cpe/cpe3/B-2.pdf
Brownell, Peter. 1982. The role of accounting data in performance evaluation, budgetary participation, and organizational effectiveness. Journal of Accounting Research, 20, 12-27.

Covaleski, M. J; Evans J. III; Luft dan M. Shields. 2003. Budgeting research: Three theoretical perspectives and criteria for elective integration. Journal of Management Accounting Research 15: 3-49.

Dawley, David D; et al.2009. Dimensionality Of Organizational Commitment In Volunteer Workers: Chamber Of Commerce Board Members And Role Fulfillment. Journal of Vocational Behavior 67 (2005) $511-525$

Dunk, A. 1993. The effect of budget emphasis and information asymmetry on the relation between budgetary participation and slack. The Accounting Review, (April), 68(2), 400-410.

Fitriyani, Fara. 2016. Tekanan Ketaatan pada Penciptaan Budgetary Slack. Tirtayasa Ekonomi. Vol 11 No.2 Tahun 2016

Ghozali, Imam. 2011. Aplikasi Analisis Multivariate Dengan Program SPSS. Badan Penerbit Universitas Diponegoro : Semarang

Hansen, D.R dan Mowen. M. 2000. Management Accounting. South Western College Publishing

Hartmann G.H Frank \& Moers Frank. 1999. Testing contingency hypotheses in Budgetary Research: An Evaluation of the use of Moderated Regression Analysis. Accounting Organizations and Society 24 page 291-315

Jermias. 2011. Budgetary Participation: The Effects of Information Asymetry, Goal Commitment, and Role Ambiguity on Job Satisfaction and Performance. SSRN

Jones, T. M. 1991. Ethical decision making by individuals in organizations: An issue-contingent model. Academy of Management Review, 15, 366-392

Kenis, Izzettin. 1979. Effect of Budgetary Goal Characteristic on Managerial Attitudes and Performance. The Accounting Review, 14 (4), hal. 707721

Kren, L. 1993. Control system effects on budget slack. Advances in Management Accounting, 2, 109-118.

Lord dan DeZoort, 2001. The Effect of Obedience Pressure and Perceived Responsibility on Management Accountants' Creation of Budgetary Slack. Behavioral Research in Accounting, Volume 18, 2006 pp. 19-35

Lukka, K. 1988. Budgetary biasing in organizations: Theoretical framework and empirical evidence. Accounting, Organization and Society, 13, 281301.

Milani, K. 1975. The relationship of participation in budget-setting to industrial supervisor performance and attitudes: A field study. The Accounting Review, 50(2), 274-284. 
Nouri H; Parker R.J. 1998. The Relationship Between Budget Participation and Job Performance: The Role of Budget Adequacy and Organizational Commitment. Accounting, organization and Society, Vol. 23, No 5/6, pp. 467-483

Schiff, M., dan A.Y. Lewin. 1970. The impact of people on budgets. The Accounting Review (April): 259-268

Sekaran, Uma. 2006. Research Methods for Business. Salemba Empat
Taylor, Shelley E., Letitia Anne Peplau dan David O. Sears (2009). Social Psychology 12th Edition. Dialihbahasakan oleh Tri Wibowo B.S., Pearson Education-Prentice Hall.

Young, S. M. 1985. Participative budgeting: The effects of risk aversion and asymmetric information on budgetary slack. Journal of Accounting Research, (Autumn), 23(2), 829-8 